\title{
Predicting Crowd Intensity Based on Statistics of Mobile Signal Analysis in Smart City Using Heatmap Layer by Fuzzy Inference and Deep Learning.
}

Revathy jayabaskar ( $\nabla$ revathyjayabaskar@gmail.com )

SASTRA Deemed University: Shanmugha Arts Science Technology and Research Academy https://orcid.org/0000-0002-0691-1687

SELVAKUMAR $k$

Annamalai University

\section{Research Article}

Keywords: mobile user, Heatmap layer, deep learning algorithm, wireless network, mobile signal

Posted Date: July 15th, 2021

DOl: https://doi.org/10.21203/rs.3.rs-610591/v1

License: (c) (i) This work is licensed under a Creative Commons Attribution 4.0 International License.

Read Full License 


\title{
Predicting Crowd Intensity Based on Statistics of Mobile Signal Analysis in Smart City using Heatmap layer by Fuzzy Inference and Deep Learning.
}

\author{
Dr G Revathy ${ }^{1}$ and Dr K.Selvakumar ${ }^{2}$ \\ 1-Assistant Professor Grade I, School of Computing, Sastra University, Thanjavur, Tamilnadu. \\ Email revathyjayabaskar@gmail.com. \\ 2-Professor and Head, Department of IT, FEAT,Annamalai University, Tamilnadu. \\ Email kskaucse@gmail.com
}

\begin{abstract}
Wireless networks the mobile user to establish a wireless connection with the central server in the fixed network. On-line activities such as transaction and querying information can be conducted by mobile user. Mobile user queries are location dependent in mobile environment. Mobile user wants to move to hospital or hypermarket, before moving to the location, mobile user wants to know the crowd at the destination, Based on the number of people present, the mobile user can choose to go to another branch. At present a mobile user cannot get the details about the crowd in the particular location. Recent researches are the vehicle tracking, taxi services, road traffic and locationbased queries. A proposed research idea is to identify the number of people present in a given area in a city. We use the Heatmap layer tool to find out the crowd intensity. Heatmap layer will indicate crowd intensity of a particular area, Heatmap layer show the color on the map, red colour in the particular location is represent about high intensity of crowd and the green colour is represent lower intensity of crowd, Heatmap shows crowd intensity through mobile signal, more people present more mobile signal in that location. In our research proposal,we calculate the people crowd using deep learning algorithm. This research application can be used in smart city for the school fees payment , Ministry office, hospital (out Patient not to wait more time in hospital), hypermarket and cinema theater. Numerical method is obtained by using the fuzzy inference model.
\end{abstract}

Keywords—mobile user, Heatmap layer, deep learning algorithm, wireless network, mobile signal

\section{INTRODUCTION}

Wireless networks, as indicated earlier, enable mobile clients to establish a wireless connection with the central server in the fixed network. On-line activities such as transaction and querying information can be conducted by clients. Mobile host queries are location dependent in mobile environment. This means that the query results are obtained based on the user's location. As mobile users frequently move from one place to another, most of the time the location information cannot be explicitly stated and attached to the queries but has to be determined by the network The location dependent query requires data that depends on location. The location dependent data are of two types, static and dynamic. In static location dependant data, the mobile users does not move which in return reduces database updation frequency. In dynamic location dependent data, database is updated frequently with the movement of mobile user from one place to another.The related issues will become more complex when they involve the client's disconnection. Therefore, it is common for a mobile client to become disconnected from the network after sending queries due to signal distortion, handoff process or limited battery power. The location of mobile user or object is identified through the reference point of geographical position on the earth. This information can be considered by using a number of different representations, including Latitude/longitude/altitude or street addresses, etc. At present, the research focuses on mobile computing to provide the data access at any place, at any time. This type of mobile devices not only uses voice communication or work locally, but also used for transmitting the data. In mobile computing, many researchers work on data management, considering continuity of development, enhancement of wireless networks and mobile computing devices, but still the limitations of data management in mobile devices are short battery lifetime, less memory processing and limited storage capacity and display sizes. The resources that mobile devices can access usually depend on the location of the user. The existing method in mobile environments is to provide the user with context aware information. In the present research, context aware factors are considered for location based services. This provides the information to the mobile user based on the location in order to minimize the requests sent to the server. 


\section{II.RELATED WORK}

In this paper [1], (Sarah Aimi Saad1, Amirah 'Aisha Badrul Hisham )-Using Real-time on-Campus Public Transportation Monitoring System Real-time update is very important in Advanced Public Transportation System (APTS). However, due to the lack of information on the bus's estimated time of arrival (ETA), current location and occupancy (number of seats available) commuters are Unenthusiastic to use public transport. The study in this paper proposed a bus tracking system that can track, display the location of the bus in present time and approximation the bus arrival time to the next bus stop. Monitoring system that consists of tracking device and web-based application for monitoring purposes is developed.The proposed method is able to track and monitor the real-time location of the bus and able to estimate the bus's arrival time to the next bus stop.In this paper, [2]( Nikki Rathore, Pramod Kumar Jain, Manoranjan Parida ).A Routing Model for Emergency Vehicles Using the Real Time Traffic, The efficiency of EMS depends on its timely Openness to the demand and the Addition of real time travel/traffic data into the vehicle scheduling and routing model. This paper focuses on Scheming the routes for emergency vehicles by developing an optimization model based on the available knowledge of real time traffic information using the Google Maps Distance Matrix API. The heuristic approach involves formulation of the vehicle routing problem as an integer programming model and optimizing it by integrating with Google API. In this paper[3]( Fu-Shiung Hsieh),- Car Pooling based on Trajectories of Drivers and Requirements of Passengers Car pooling is a collective transportation model based on shared use of private cars. The objective of carpooling is to reduce the number of cars in use by grouping people. By exploiting car pooling model, it can significantly reduce congestion, fuel consumption, air pollution, parking demands and commuting costs. This paper aims to develop a prototype car pooling system to match passengers and drivers based on their trajectories. We propose a heuristic method to solve the car pooling problem. Matching algorithm that is seamlessly integrated with Google Maps API, dynamic web pages and database system. We also conduct experiments to illustrate our proposed method. In this paper[4] (Vikky Aprelia Windarni, Eko Sediyono),-Using GPS and Google Maps for Mapping Digital Land Certificates Google maps API provides many features for manipulating maps and adding content to the map through a variety of services that allows to create a mapping application. This paper discusses the use of the Google maps API to connect the land site listed in the certificate of land with Google maps so that the location of the land can be determined accurately. The method used in this research is the research and development $(\mathrm{R} \& \mathrm{D})$ method with dynamic system approach. The applications were made aiming to help the Land Officer and the public to know the location of the land digitally. The utilization of GPS technology is used to determine the coordinate points of the boundary in the form of latitude and longitude accordance with the existing situation in the field. In this paper[5]( Dhiraj Sunehra , Pottabathini Laxmi Priya, and Ayesha Bano),- Monitoring of Children Location on Google Maps GPS and GSM Technologies human safety and security has become an important issue. In this paper a prototype Children Location Monitoring System (CLMS) is implemented using Global Positioning System (GPS) and Global System for Mobile communication (GSM) technologies. The system is built on ARM \& LPC2148 microcontroller board and uses a commercial GPS receiver to compute the position of the child continuously. The child's position information is periodically sent through GSM to the parent's smart phone (as Google Map Link).

\section{PROPOSED SYSTEM}

Location based services processing is illustrated in (Figure 1). When a mobile user sends a request to the server, the server finds the mobile user location through google map and search for the reply to the particular query, based on the location of the mobile user. Once the result is found from the database, reply is sent to the mobile user. The location based services are mainly used for roadside assistance, digital travel assistance and supermarket tracking services An example of Location based services (LBS) architecture is shown in (Figure 2 ). The user needs a taxi cabs and sends a query to the server. Location dependent queries are based on the user location of continuous query. 


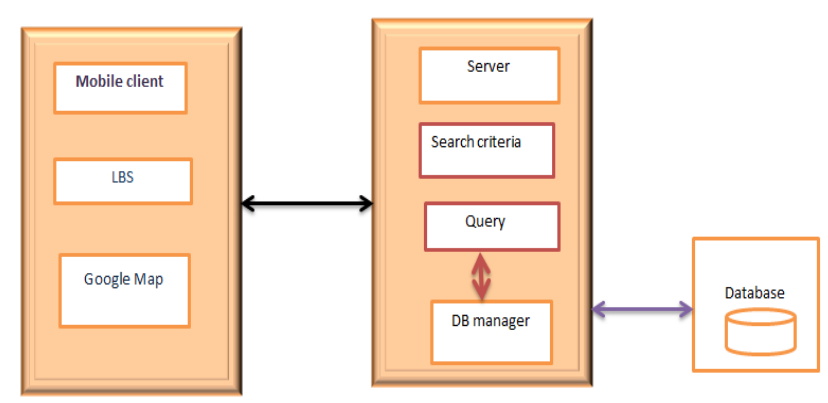

Fig 1: Location based service processing in mobile Environment

For each query from the user, the server finds the location of the user and sends a reply to the query. Research challenge is the query processing with location constraints of mobile user. Latest research on location dependent data management involves consistency maintenance. When mobile user moves, its location value changes. The proposed method to find the crowd intensity for the particular location, so user can decide to move to the location or another location.

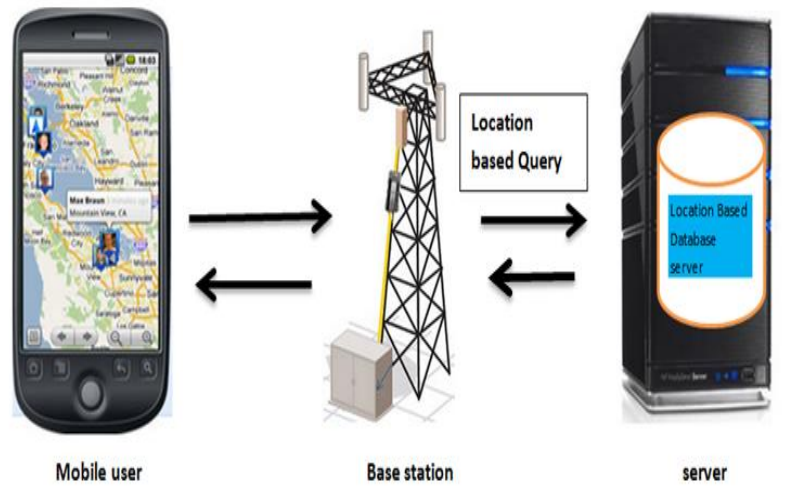

Fig 2: LBS system architecture

\section{A.Deep Learning Algorithm}

In this research paper, we used the deep learning algorithm to find the total crowd for the particular area, it gives the better results, we have taken the latitude and longitude of the data as the input for the formula and calculate the total population.

$\mathrm{DP}=\mathrm{N} / \mathrm{A}$

$\mathrm{DP}=$ Density of population

$\mathrm{N}=$ Total Population/ Number of people

$\mathrm{A}=$ Land area covered by that population

The components and the architecture of the proposed SBU-LSTM is detailly introduced in this section. Here, speed prediction is defined as predicting future speed based on historical speed information. The illustrations of the models in following sub-sections all take the traffic speed prediction as examples.

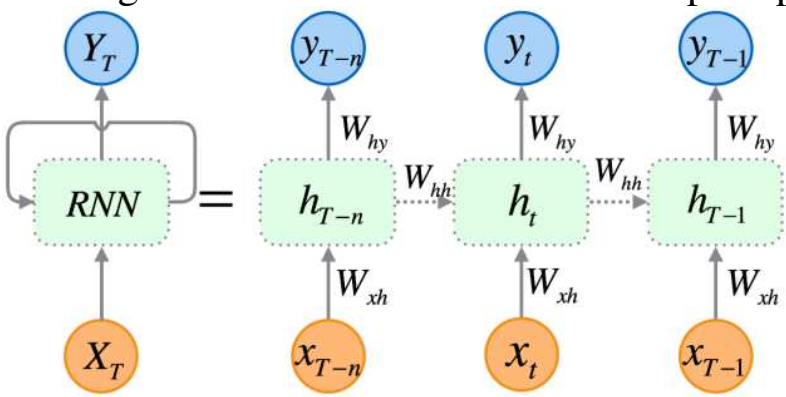

Standard RNN for time steps 
To handle the aforementioned problems of RNNs, several sophisticated recurrent architectures, like LSTM architecture and Gated Recurrent Unit (GRU) architecture are proposed. It has been showed that the LSTMs work well on sequence-based tasks with long-term dependencies, but GRU,a simplified LSTM architecture, is only recently introduced and used in the context of machine translation. Although there

are a variety of typical LSTM variants proposed in recent year,a large-scale analysis of LSTM variant shows that none of the variants can improve upon the standard LSTM architecture significantly .

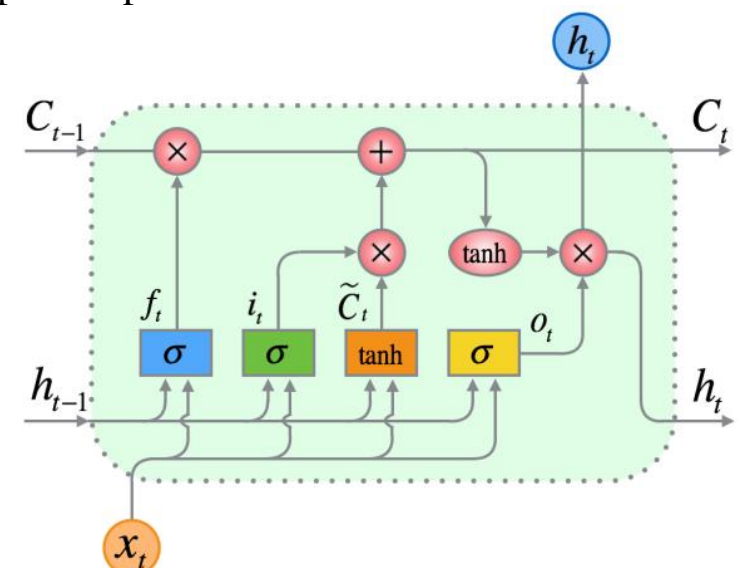

LSTM Architecture

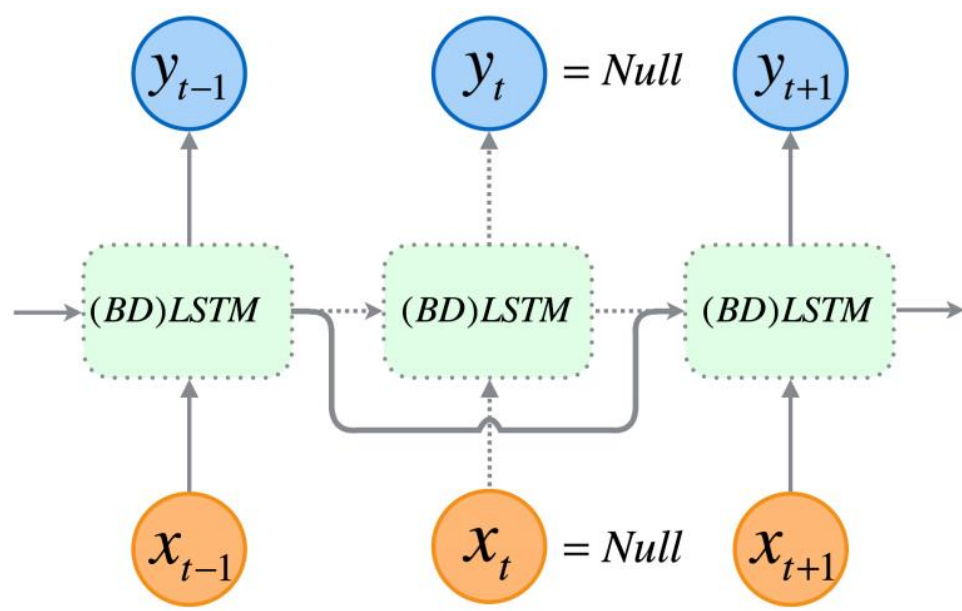

Masking Layer LSTM

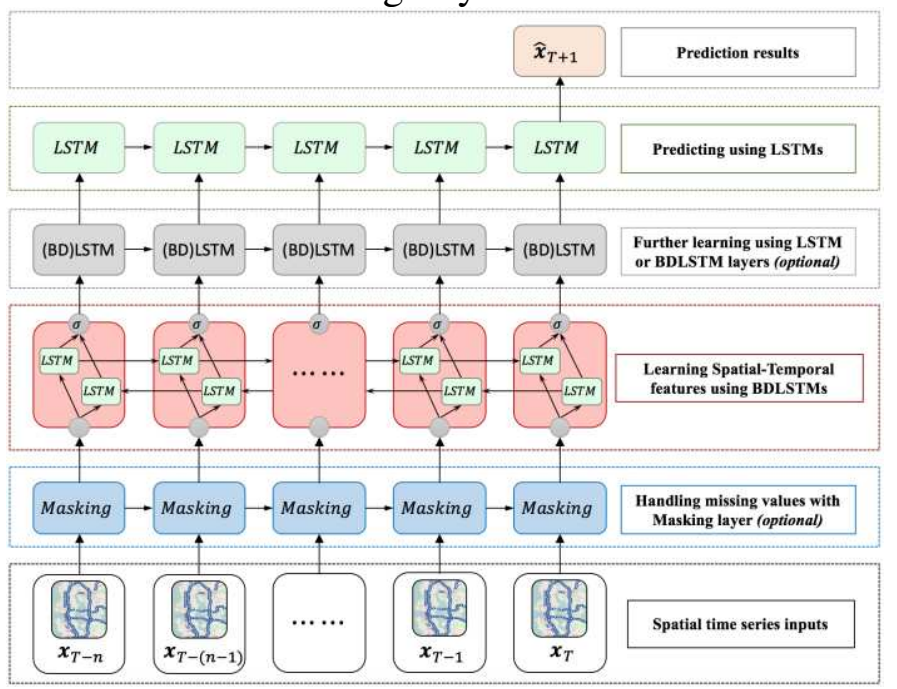

Submasking LSTM Architecture

\section{Numerical result}

The goal of this study is to assemble the fuzzy inference model to expect the Frequency of mobile communication primarily based on Mall and Public. In this process we used 7 data for the entire week, which contain Mall, Public and Frequency of mobile communication.

Table 1. Mall, Public and Frequency of mobile communication.

\begin{tabular}{|l|l|l|l|}
\hline & Mall(\%) & Public & Frequency of \\
\hline
\end{tabular}




\begin{tabular}{|l|l|l|l|}
\hline & & & $\begin{array}{l}\text { mobile } \\
\text { communication }\end{array}$ \\
\hline D1 & 1.25 & 0.590 & 0.700 \\
\hline D2 & 1.02 & 0.620 & 0.072 \\
\hline D3 & 1.36 & 0.580 & 0.810 \\
\hline D4 & 2.01 & 0.620 & 0.750 \\
\hline D5 & 2.13 & 0.581 & 0.850 \\
\hline D6 & 2.45 & 0.593 & 0.900 \\
\hline D7 & 0.53 & 0.612 & 0.900 \\
\hline
\end{tabular}

In the above table there are 7 pair of input and output data. The Mall, Public and Frequency of mobile communication are denoted in the universal set as $\mathrm{P}=[0,4], \mathrm{Q}=[0.5,0.9]$ and $\mathrm{R}=[0.5,1]$ respectively. Working with linguistic term such as Low(L), Medium (M) and High(H). The characterization of fuzzy set for triangular and trapezoidal membership function are given below

$\mu_{P_{L}}(x)= \begin{cases}1 & \text { if } x \leq 0.5 \\ 1.5-x & \text { if } 0.5 \leq x \leq 1.5 \\ 0 & \text { if } x \geq 1.5\end{cases}$
$\mu_{P_{M}}(x)= \begin{cases}x-0.5 & \text { if } 0.5 \leq x \leq 1.5 \\ 2.5-x & \text { if } 1.5 \leq x \leq 2.5 \\ 0 & \text { if } x \leq 0.5 \text { (or }) x \geq 2.5\end{cases}$

$\mu_{P_{H}}(x)= \begin{cases}1 & \text { if } x \geq 2.5 \\ x-1.5 & \text { if } 1.5 \leq x \leq 2.5 \\ 0 & \text { if } x \leq 1.5\end{cases}$

$\mu_{Q_{L}}(x)= \begin{cases}1 & \text { if } x \leq 0.58 \\ \frac{0.60-x}{0.02} & \text { if } 0.58 \leq x \leq 0.6 \\ 0 & \text { if } x \geq 0.6\end{cases}$

$\mu_{Q_{M}}(x)= \begin{cases}\frac{x-0.58}{0.02} & \text { if } 0.58 \leq x \leq 0.6 \\ \frac{0.62-x}{0.02} & \text { if } 0.6 \leq x \leq 0.62 \\ 0 \quad \text { if } x \leq 0.58(\text { or }) x \geq 0.62\end{cases}$

$\mu_{Q_{H}}(x)= \begin{cases}1 & \text { if } x \geq 0.62 \\ \frac{x-0.6}{0.02} & \text { if } 0.6 \leq x \leq 0.62 \\ 0 & \text { if } x \leq 0.6\end{cases}$

$\mu_{R_{L}}(x)= \begin{cases}1 & \text { if } x \leq 0.7 \\ 0.8-x & \text { if } 0.7 \leq x \leq 0.8 \\ 0 & \text { if } x \geq 0.8\end{cases}$

$\mu_{R_{M}}(x)= \begin{cases}x-0.7 & \text { if } 0.7 \leq x \leq 0.8 \\ 0.9-x & \text { if } 0.8 \leq x \leq 0.9 \\ 0 & \text { if } x \leq 0.7 \text { (or) } x \geq 0.9\end{cases}$ 
$\mu_{R_{H}}(x)= \begin{cases}1 & \text { if } x \geq 0.9 \\ x-0.8 & \text { if } 0.8 \leq x \leq 0.9 \\ 0 & \text { if } x \leq 0.8\end{cases}$

Figure 1. Graph membership function for Mall

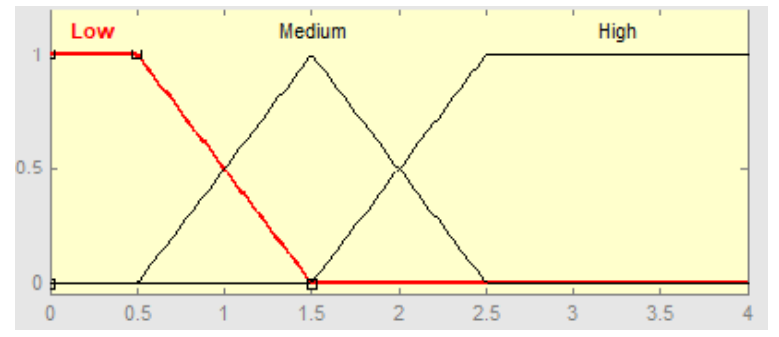

Figure 1. Graph membership function for mall

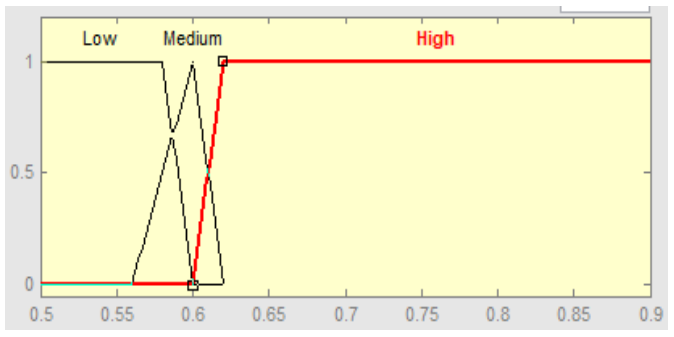

Figure 2. Graph membership function for public

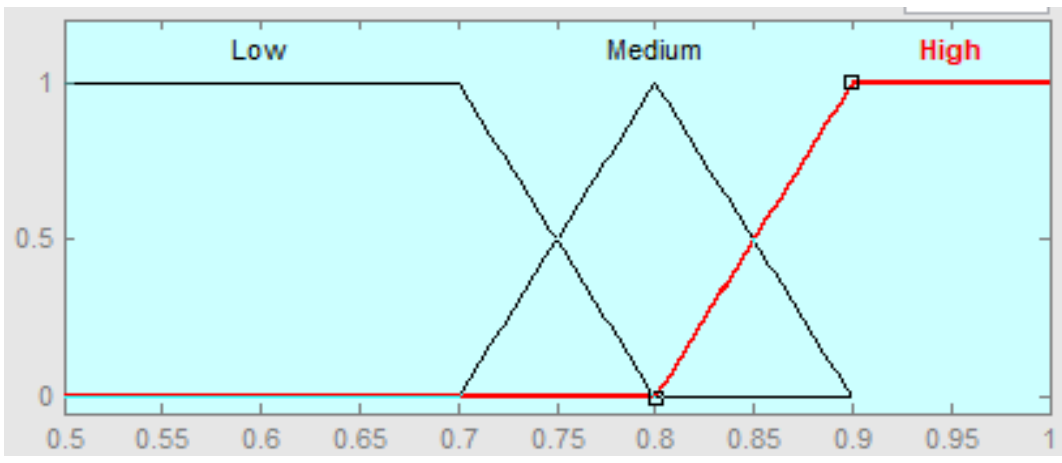

Figure 3. Graph membership function for Frequency of mobile communication

We need to fuzzify each pair of input and output data by membership function defined for Mall, Public and Frequency of mobile communication. For the input and output data we can generate 7 rule.

Table 2. Mall, Public and Frequency of mobile communication mobile signal

\begin{tabular}{|l|l|l|l|l|l|l|l|}
\hline \multirow{2}{*}{ Rule } & If & Mublic & $\begin{array}{l}\text { Frequency of } \\
\text { mobile } \\
\text { communication }\end{array}$ & Mall & Public & $\begin{array}{l}\text { Frequency of } \\
\text { mobile } \\
\text { communication }\end{array}$ & Multiplication \\
\hline 1 & L & M & L & 0.25 & 0.5 & 1 & 0.1250 \\
\hline 2 & L & H & M & 0.48 & 1 & 0.02 & 0.0096 \\
\hline 3 & L & L & M & 0.14 & 1 & 0.09 & 0.0126 \\
\hline 4 & M & H & H & 0.49 & 1 & 0.05 & 0.0245 \\
\hline 5 & M & L & M & 0.37 & 0.95 & 0.05 & 0.0175 \\
\hline 6 & H & M & H & 0.95 & 0.65 & 1 & 0.6175 \\
\hline 7 & L & H & H & 0.97 & 0.6 & 1 & 05820 \\
\hline
\end{tabular}

Rule after reduction is given as,

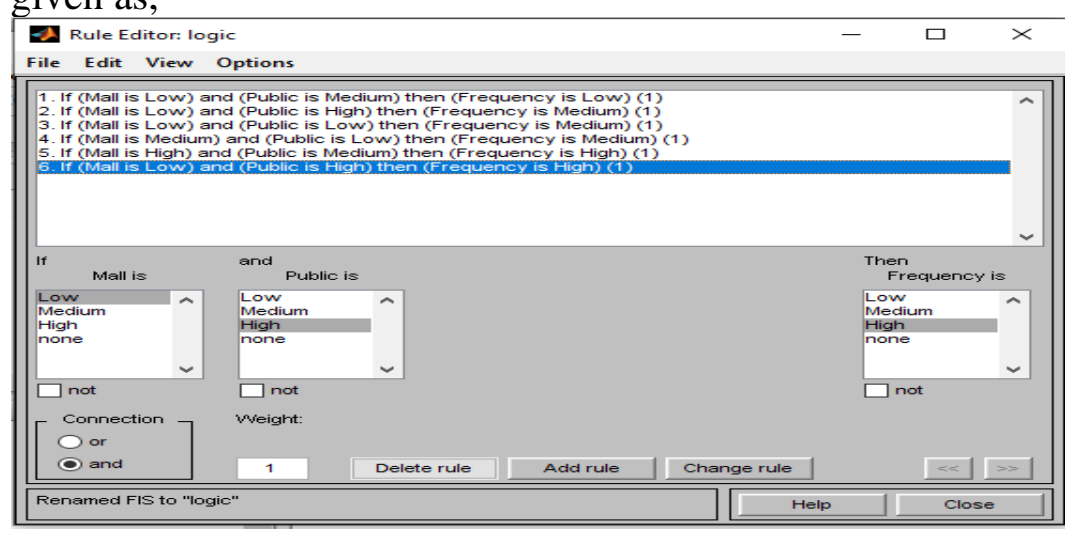


The fuzzy inference model predicts the percentage as $92.56 \%$.

\section{IV.DISCUSSION}

Research paper, we used the java desktop using netbeans IDE and glassfish server for handling the http request, to find the particular location using Google API and mysql database, java script, CSS and HTML used for the design. We used Heat map for the Crowd intensity analysis. Heat Map crowd intensity prediction based on mobile users. The Heat map Layer provides client side rendering of heat maps. A heat map is a visualization used to depict the intensity of data at geographical points. When the Heat map Layer is enabled, a colored overlay will appear on top of the map. By default, areas of higher intensity will be colored red, and areas of lower intensity will appear green. So we can identify that more mobile user the heat map shows the colored and less mobile user the heat map shows the green color In this research paper the output shows the real time crowd intensity for a particular place using the Google map. In our system the user can enter the particular place to visit and click the search button showing for the real time crowd using heat map. Google map and proposed method analyses the crowd intensity using mobile signal in particular place. proposed system display more or less population for the particular location to the user. In this research we used Deep Learning Algorithm to calculate crowd for the particular location.Figure 3 show the muscat city hospitals, figure 4 show the muscat city NMC Speciality Hospital, shows green color, so the crowd is less . Figure 5 shows the muscat theatre, shows many theatres in the muscat city map with more crowd. Figure 6 shows the VOX cinema MGM Muscat, shows more crowd .Figure 7 shows Qatar country hospitals,shows more crowd in all the hospitals . Figure 8 show Al Emadi Hospital, shows more crowd .

\section{A.Screen Shots}

Muscat for Hospital

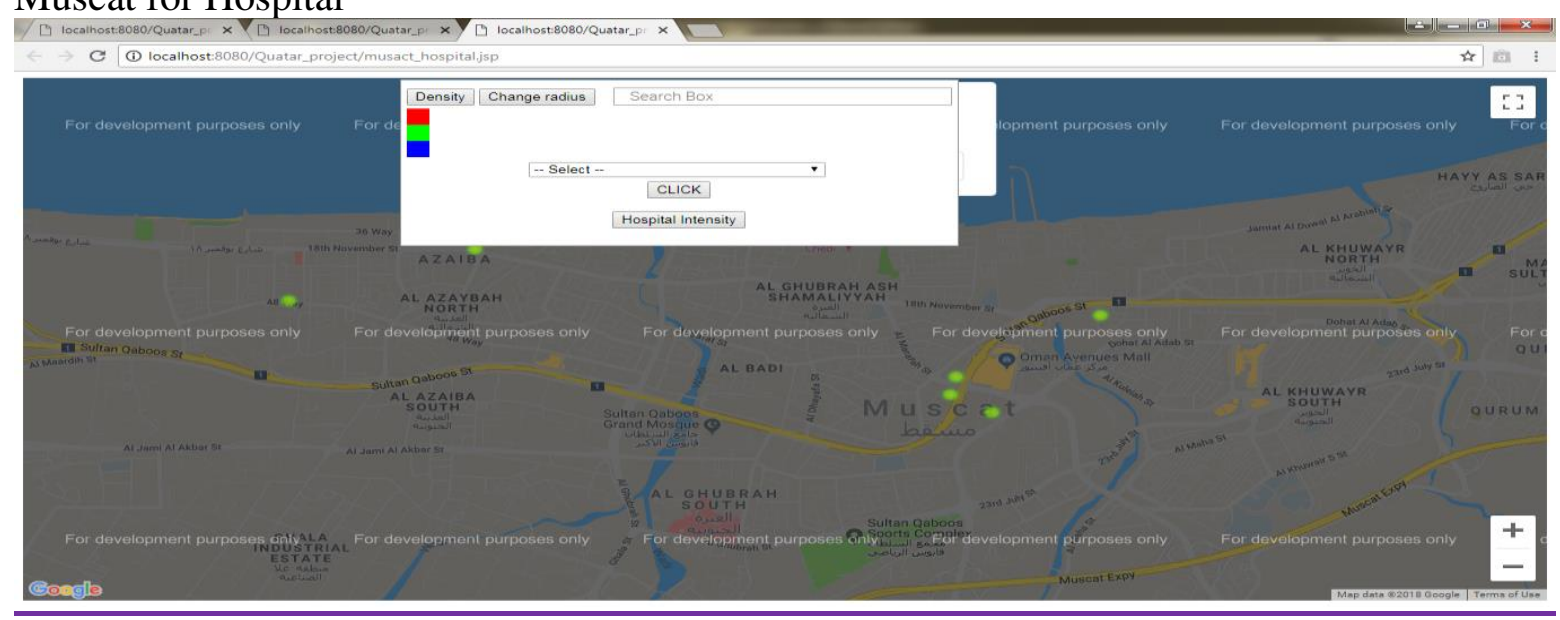

Fig 3 :Muscat for Hospital

Searching for NMC Specialty Hospital Muscat

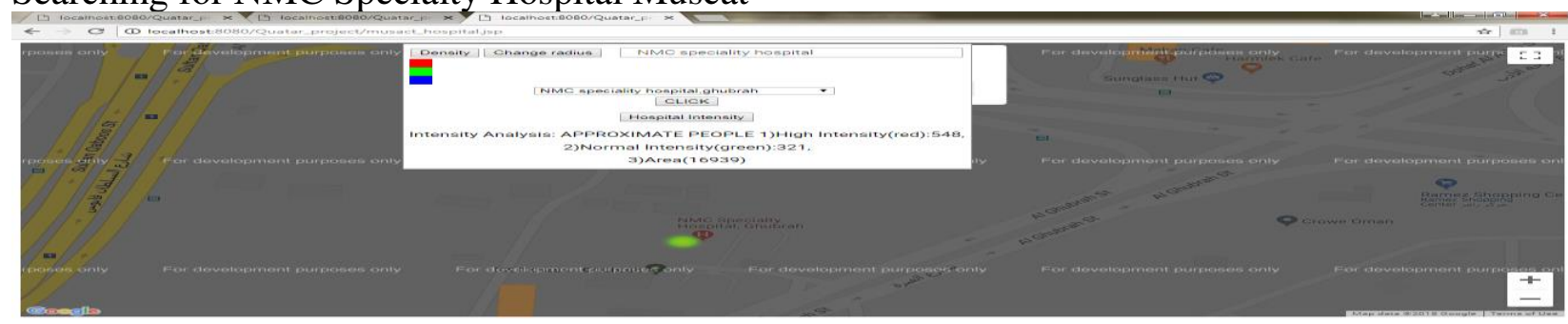

Fig 4 MMC Specialty Hospital MusCAT 


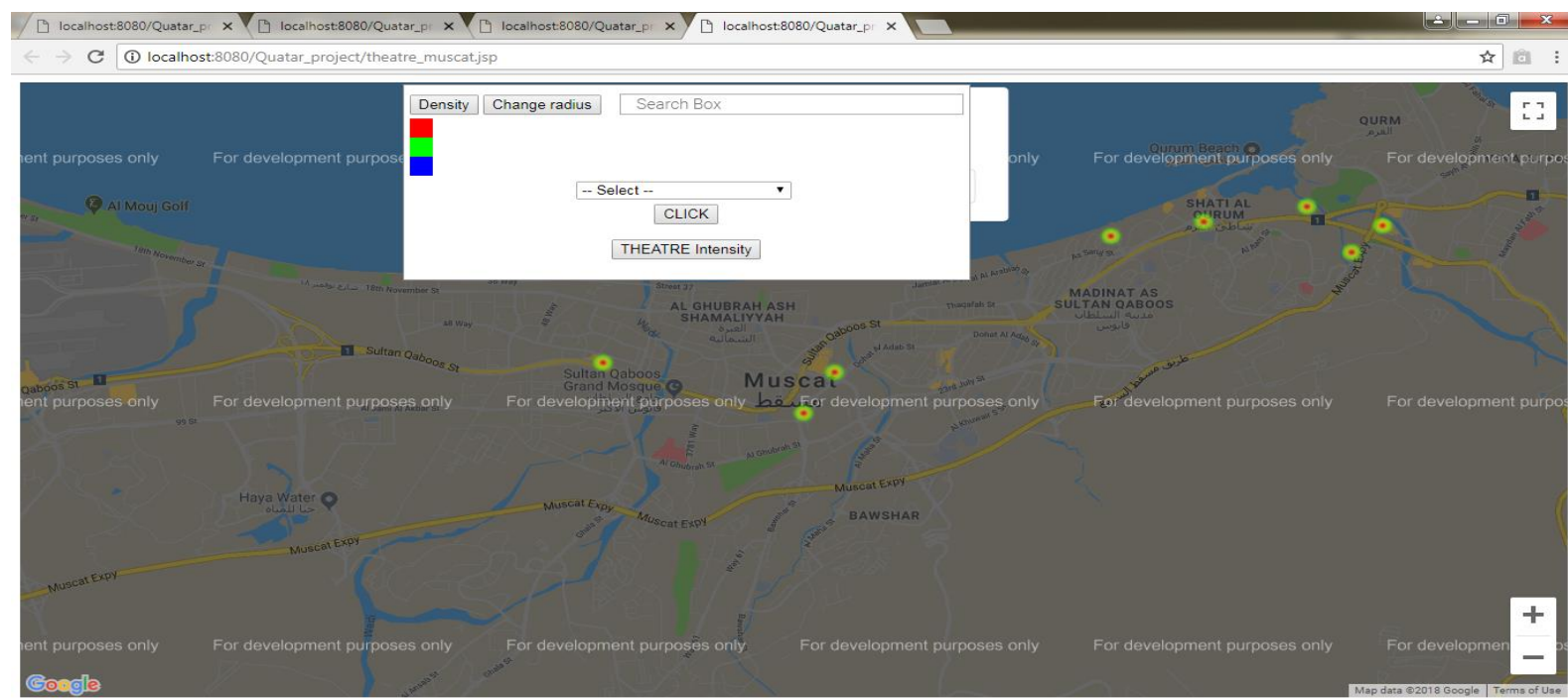

Fig 5: Muscat For Theatres

\section{Searching For Vox Cinema Mgm Muscat}

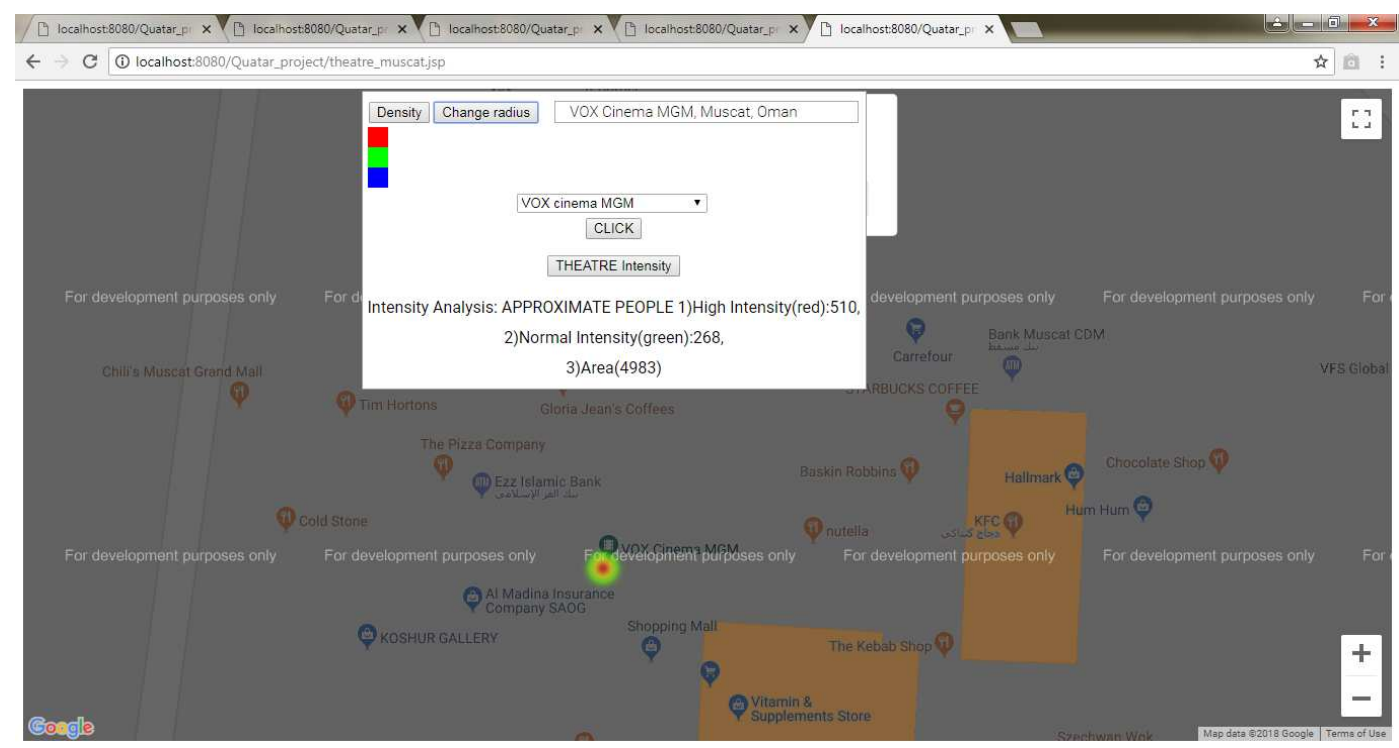

Fig 6 : Vox Cinema Mgm Muscat

Qatar Hospitals 


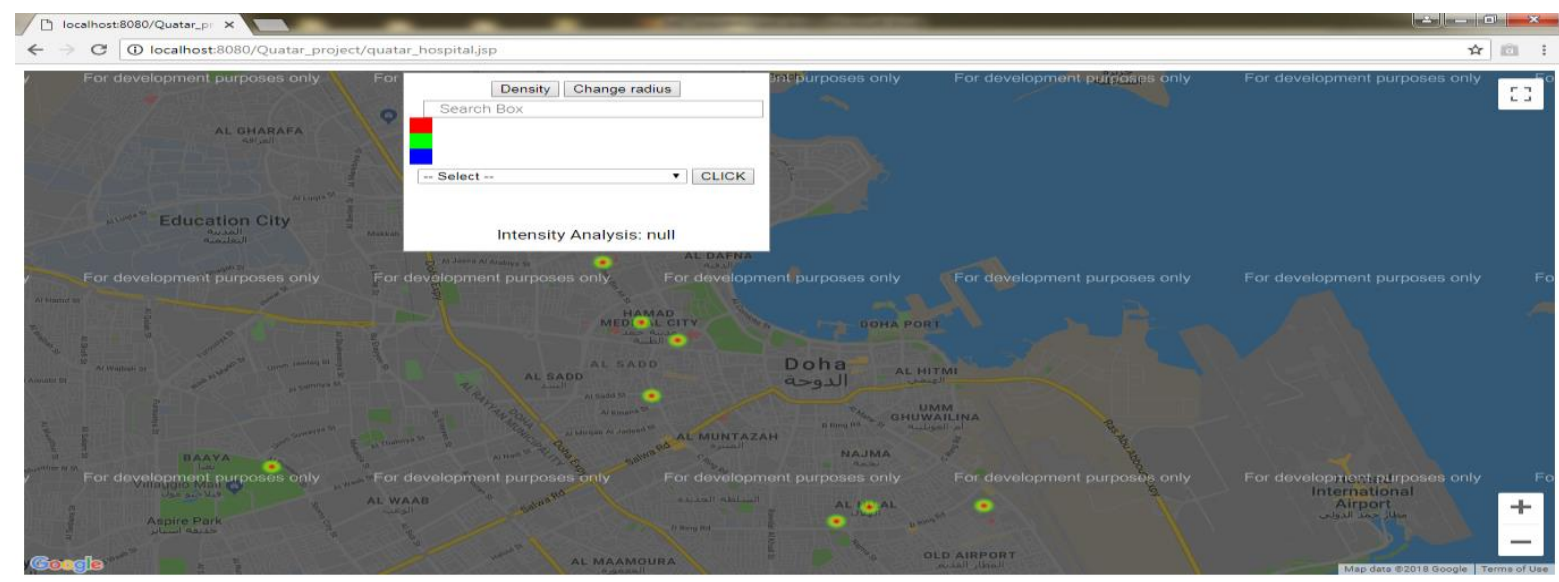

Fig 7: Qatar for Hospital

Searching for Al Emadi Hospital

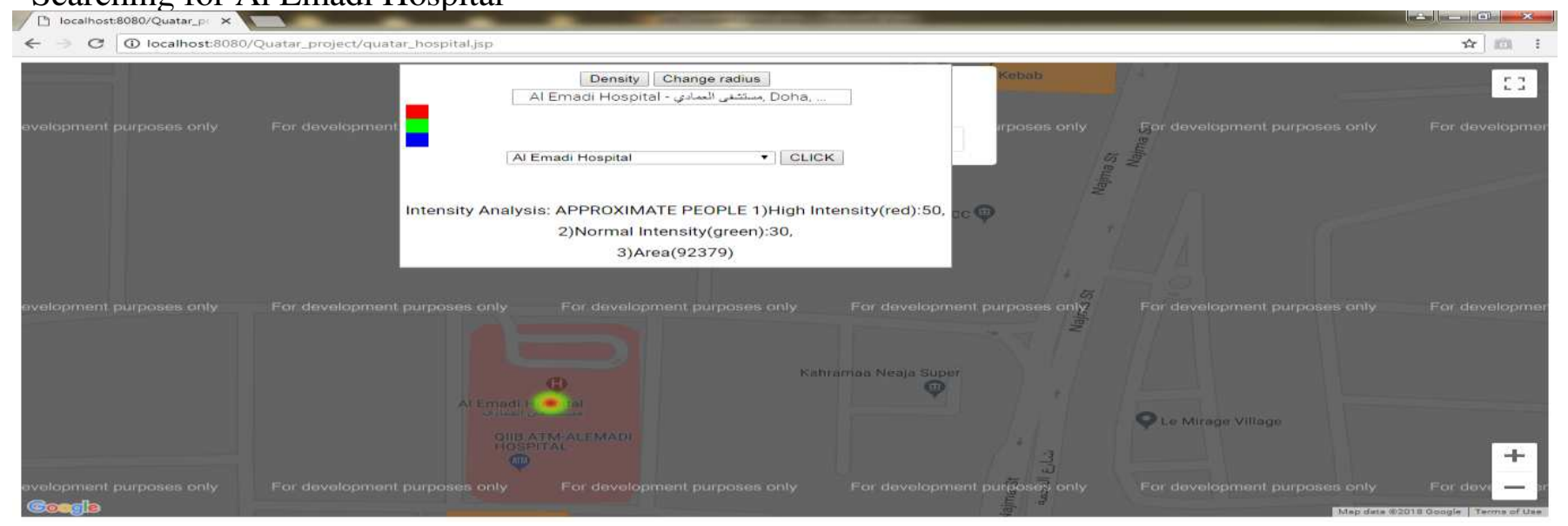

IG 8 Al EMADI HOSPITAL IN QATAR

\section{Conclusion}

In this paper, present a new research idea to identify the number of people present in the given area in the city . The proposed system output shows the crowd intensity for the user request, based on the crowd, the user can decide to move to a particular location or another location. The research application is very useful in smart city for school fees payment, Ministry office, hospital (busy time in hospital), hypermarket and cinema theater. The application is very useful for the benefit of the customer. To master these challenges fuzzy inference method is very appropriate.

\section{REFERENCES}

1. Dr G.Revathy, Ms Anju, Parimalam and Imaya Kanishka, "Diabetic Detection Using Irish", International Journal of Scientific Research in Engineering and Management (IJSREM), Volume: 04 Issue: 03 | Mar -2020 ISSN: 2582-3930

2. Dr.G.Revathy, N.S.Kavitha, K.Senthivadivu. D.Sathya and P.Logeshwari , "Girl Child Safety using IoT Sensors and Tabu Search Optimization" International Journal of Recent Technology and Engineering (IJRTE) ISSN: 2277-3878 volume 8, January 2020.

3. Dr.G.Revathy, Dr.G.Saravanan, Dr.R.Madonna Arieth and Mr.M.Vengateshwaran, “

Magnify Qos with Tabu \& Link Scheduling In Wmn”, International Journal of Recent Technology and Engineering (IJRTE) ISSN: 2277-3878, Volume-8, Issue-4, November 2019

4. Mrs G.Revathy , "Mounting Eminence of services in wireless mesh networks", International journal of Research and Analytical reviews, sep 2018(ISSN 2349 5138)

5. Mrs.G.Revathy and Dr.K.Selvakumar, "Sustain route by tabu and amplified qos by distributed scheduling in wmn", International Journal of Recent trends in Enginnering and research (ISSN: 0973-7391). 
6. Mrs.G.Revathy and Dr.K.Selvakumar, "Channel assignment using tabu search in wireless mesh networks",Wireless personal communication ISSN NO 09296212.

7. Mrs.G.Revathy and Dr.K.Selvakumar,'Increasing quality of services in wireless mesh networks", International journal of advanced research in computer engineering and technology, vol 7, issue 3, march 2018. ISSN 22781323

8. Mrs.G.Revathy and Dr.K.Selvakumar, "Escalating quality of services with channel assignment and traffic scheduling in wireless mesh networks", Cluster computing, Jan 2018. ISSN no 13867857.

9. Mrs G.Revathy and Dr.K.Selvakumar, "Route maintenance using tabu search and priority scheduling in wireless mesh networks", Journal of advanced research in dynamical and control systems, vol 9,sp-6, 2017. ISSN 1943023X

Funding

There are no funding required

${ }^{*}$ Conflicts of interest/Competing interests

No

${ }^{*}$ Availability of data and material (data transparency)

\begin{tabular}{|l|l|l|l|}
\hline & Mall(\%) & Public & $\begin{array}{l}\text { Frequency of } \\
\text { mobile } \\
\text { communication }\end{array}$ \\
\hline D1 & 1.25 & 0.590 & 0.700 \\
\hline D2 & 1.02 & 0.620 & 0.072 \\
\hline D3 & 1.36 & 0.580 & 0.810 \\
\hline D4 & 2.01 & 0.620 & 0.750 \\
\hline D5 & 2.13 & 0.581 & 0.850 \\
\hline D6 & 2.45 & 0.593 & 0.900 \\
\hline D7 & 0.53 & 0.612 & 0.900 \\
\hline
\end{tabular}

\begin{tabular}{|c|c|c|c|c|c|c|c|}
\hline \multirow[t]{2}{*}{ Rule } & \multicolumn{2}{|l|}{ If } & Then & \multicolumn{4}{|c|}{ Membership } \\
\hline & Mall & Public & $\begin{array}{l}\text { Frequency of } \\
\text { mobile } \\
\text { communication }\end{array}$ & Mall & Public & $\begin{array}{l}\text { Frequency of } \\
\text { mobile } \\
\text { communication }\end{array}$ & Multiplication \\
\hline 1 & $\mathrm{~L}$ & $\mathrm{M}$ & $\mathrm{L}$ & 0.25 & 0.5 & 1 & 0.1250 \\
\hline 2 & $\mathrm{~L}$ & $\mathrm{H}$ & $\mathrm{M}$ & 0.48 & 1 & 0.02 & 0.0096 \\
\hline 3 & $\mathrm{~L}$ & $\mathrm{~L}$ & $\mathrm{M}$ & 0.14 & 1 & 0.09 & 0.0126 \\
\hline 4 & $\mathrm{M}$ & $\mathrm{H}$ & $\mathrm{H}$ & 0.49 & 1 & 0.05 & 0.0245 \\
\hline 5 & $\mathrm{M}$ & $\mathrm{L}$ & $\mathrm{M}$ & 0.37 & 0.95 & 0.05 & 0.0175 \\
\hline 6 & $\mathrm{H}$ & $\mathrm{M}$ & $\mathrm{H}$ & 0.95 & 0.65 & 1 & 0.6175 \\
\hline 7 & $\mathrm{~L}$ & $\mathrm{H}$ & $\mathrm{H}$ & 0.97 & 0.6 & 1 & 05820 \\
\hline
\end{tabular}

${ }^{*}$ Code availability

Deep learning is built using Rapid miner and Orange

Research paper, we used the java desktop using netbeans IDE and glassfish server for handling the http request

*Authors' contributions

Both authors have equally contributed in this work. 


\section{Supplementary Files}

This is a list of supplementary files associated with this preprint. Click to download.

- UniqloFastRetailing20122016Trainingstocks20122016.csv

- governmentcabinetmembersDFE.csv 